\title{
Design and realization library management system based on VB
}

\author{
Jun $\mathrm{Ji}^{1}$, Fei-Fei Xing ${ }^{2}$, Jun Du${ }^{1}$, An-Da Xiang ${ }^{1}$, Fu-Yu Wang ${ }^{1}$ \\ ${ }^{1}$ Beijing Polytechnic, Beijing 100176 China \\ ${ }^{2}$ BMEI CO., LTD., Beijing 100027, China
}

Keywords: Book management system; Visual Basic; Access database

Abstract: This paper designs the books management system's in the Windows environment. The system mainly adopts the visual design environment-Visual Basic and Microsoft Office Access as a development tool. According to the software system development process, the system can realize the current situation of the library on the basis of the require, meet demand analysis, system function general design, system function detailed design.

\section{Introduction}

Book management system is a typical application of managing information system (MIS), its development mainly includes the establishment and maintenance of database[1]. The system can meet the data consistency and integrity and security of data and the application functional characteristics [2-4]. Therefore, the user can combines type opening into the library, access database management system, the application of the VB program design of the study and application, mainly complete the books management system demand analysis, function module division, database model analysis, and database structure and application[5].

\section{System overall design}

\section{System function structure}

According to demand analysis, the system designs books management system functional structure, as shown in the Figure 1.

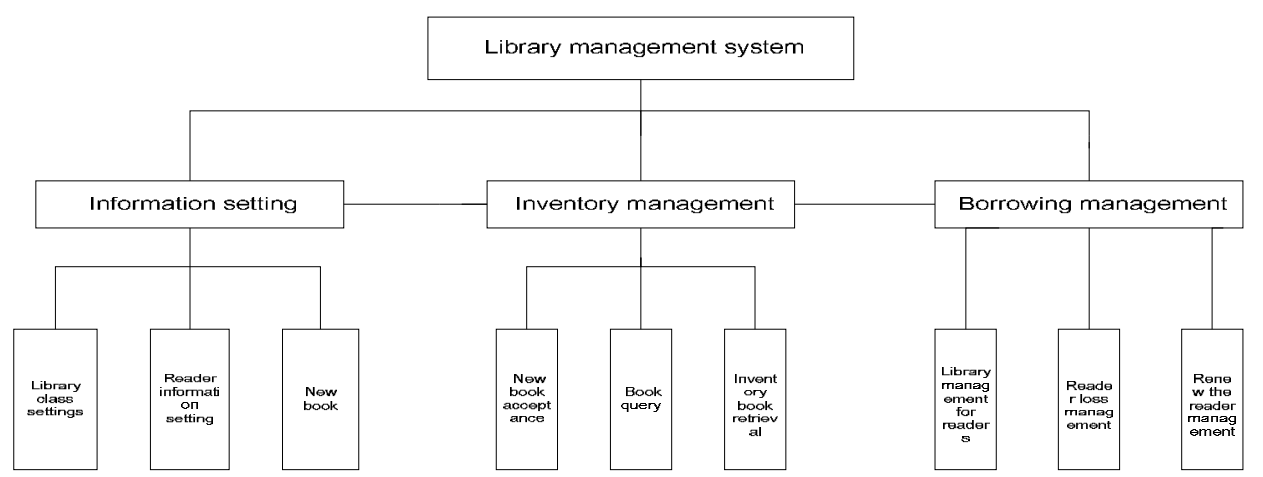

Fig.1. books management system functional structure

\section{Business process diagrams}

Books management system business process diagrams as is shown in the Figure 2. 


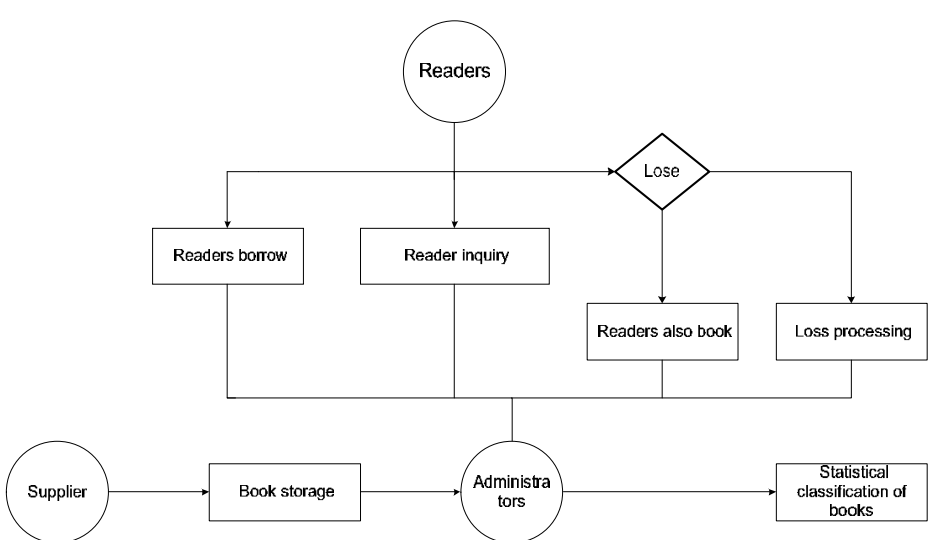

Fig.2. Books management system business process diagrams

\section{Books management system database design}

From the above function structure and entity relationship diagram, the system design function modules and shows that its detailed introduction is as follows:

1) System management module-for log in, new user operation, etc.

2) The reader management module-operation for new readers, editors, readers.

3) Online library management module-used for operation of new books, edit and delete books.

4) Book query management module-query operation for library books.

5) Library management module-used to return book lending, book and book lending record query operation.

6) System information module-software is used to display information and exit.

\section{The database table design}

According to the above on the system requirement analysis, system design, planning out the system used in the data entities.

The following will introduce a few key entities E-R diagram.

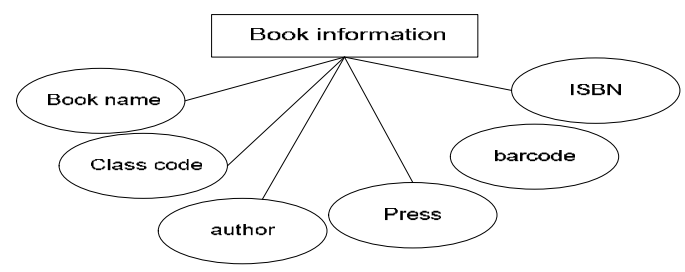

Fig.3. book entities of E-R diagram

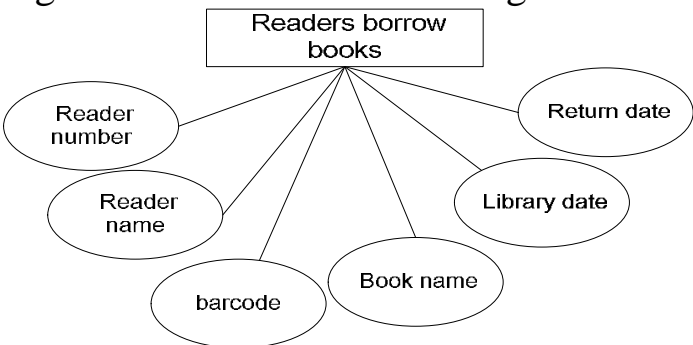

Fig.5. readers borrow entity E-R diagram

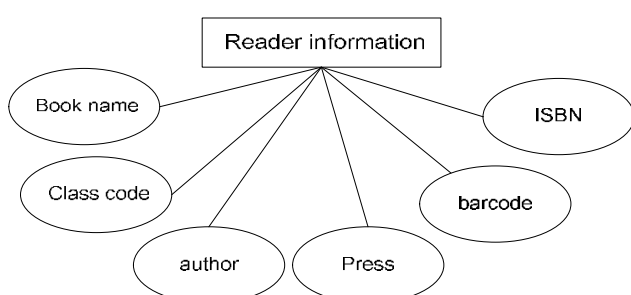

Fig.4. readers entity of E-R diagram

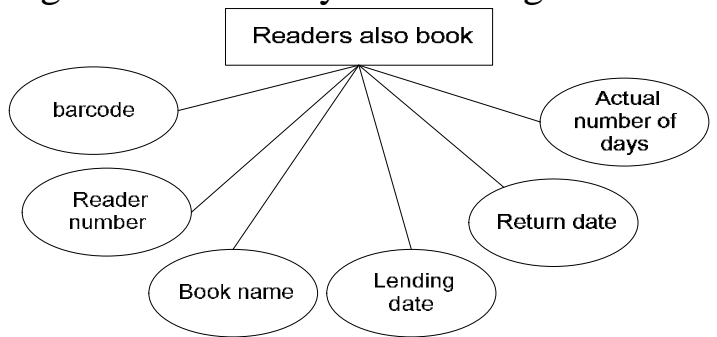

Fig.6. readers also entity E-R diagram

\section{The database logic design}

According to design good E-R diagram, the system creates data in the database table, the system database of each table in the following structure.

1) Book 
Table 1 the structure of the table book

\begin{tabular}{|c|c|c|}
\hline Field name & data type & Field size \\
\hline Book name & text & 50 \\
\hline Class code & text & 20 \\
\hline author & text & 20 \\
\hline Press & text & 30 \\
\hline Order price & currency & \\
\hline Number of copies & Number (decimal) & \\
\hline Enclosure & text & 10 \\
\hline barcode & text & 30 \\
\hline
\end{tabular}

\section{2) Reader}

Table 2 Reader table structure

\begin{tabular}{|c|c|c|}
\hline Field name & data type & Field size \\
\hline barcode & text & 30 \\
\hline Reader number & text & 50 \\
\hline Book name & text & 50 \\
\hline Book price & currency & \\
\hline Press & text & 30 \\
\hline author & text & 20 \\
\hline Specified number of days & Number (decimal) & 10 \\
\hline Lending date & Date / time & 30 \\
\hline Return date & Date / time & \\
\hline Actual number of days & Number (decimal) & \\
\hline Real date & Date / time & \\
\hline Exceed the number of days & Number (decimal) & \\
\hline
\end{tabular}

3) Borrow

Reader's information consists of in the table of information, its structure as is shown in Table 3 . Table 3 borrowb structure

\begin{tabular}{|c|c|c|}
\hline Field name & data type & Field size \\
\hline barcode & text & 30 \\
\hline Reader number & text & 50 \\
\hline Book name & text & 50 \\
\hline Book price & currency & \\
\hline Press & text & 30 \\
\hline author & text & 20 \\
\hline Specified number of days & Number (decimal) & 10 \\
\hline Lending date & Date / time & 30 \\
\hline Return date & Date / time & \\
\hline Actual number of days & Number (decimal) & \\
\hline Real date & Date / time & \\
\hline Exceed the number of days & Number (decimal) & \\
\hline
\end{tabular}

4) Return

Readers also presents book table stores the readers of books information, its structure as is shown in Table 4. 
Table 4 returnb structure

\begin{tabular}{|c|c|c|}
\hline Field name & data type & Field size \\
\hline barcode & text & 30 \\
\hline Reader number & text & 50 \\
\hline Book name & text & 50 \\
\hline Book price & currency & \\
\hline Press & text & 30 \\
\hline author & text & 20 \\
\hline Specified number of days & Number (decimal) & \\
\hline Lending date & Date / time & \\
\hline Return date & Date / time & \\
\hline Actual number of days & Number (decimal) & \\
\hline Real date & Date / time & \\
\hline Exceed the number of days & Number (decimal) & \\
\hline
\end{tabular}

\section{Conclusion}

This article designs the books management system based on Visual Basic and Access, realizes the reader's information registration, returns the book library module, etc...

\section{Reference}

[1] Chunyu-Ni, Shu Xiong Visual Basic foundation and case development [M], tsinghua university press, 2009-7.

[2] Jeffrey p. cManus Xuesuo-Zhao, Bo Gong, zhi li, Tianwe-Cao etc. Visual Basic 6.0The inventory data access technology $[\mathrm{M}]$. Beijing: tsinghua university press, 2000:156-170.

[3] ying Li, how to understand and grasp the Access [J]. Journal of new west end, 2007 (12) : 66-68.

[4] Haoqiang-Tan,Jimin-Shi,Guanquan-Tang.The Access application system development tutorial [M]. Beijing: tsinghua university press club, 2004-6-9.

[5] Shixuan-Sa, shan Wang, introduction to database system (third edition) [M]. Beijing: higher education press, 2000:10-11. 